\title{
Assessment of Implantable Cardioverter-Defibrillator Used in Heart Failure with Reduced Ejection Fraction as Primary Prevention in an Underserved Population
}

\author{
Yifan Lu, MD, MS, Ningxin Wan, MD, Nidhi Madan, MD, Ninel Hovnanians, MD, \\ Juan Carlos Ruiz Diaz, MD, Panagiota Christia, MD, and Robert Faillace, MD, ScM \\ Jacobi Medical Center, Albert Einstein College of Medicine, Bronx, NY, USA.
}

J Gen Intern Med 33(11): 1854-6

DOI: $10.1007 / \mathrm{s} 11606-018-4544-1$

(c) Society of General Internal Medicine 2018

\section{INTRODUCTION}

Implantable cardioverter-defibrillator (ICD) implantation has been one of the milestones in the treatment of heart failure providing a significant survival benefit. ${ }^{1,2}$ Current guidelines $^{3,4}$ recommend that patients who have a sustained low left ventricular ejection fraction (LVEF) of $35 \%$ or less should be evaluated for ICD for primary prophylaxis (P-ICD). Our study aimed to investigate the use of P-ICD and associated outcomes in Jacobi Medical Center, a municipal New York City public teaching hospital serving an inner-city patient population located in Bronx, NY.

\section{METHODS}

Our study was a retrospective cohort study of patients with at least one admission with the diagnosis of congestive heart failure (International Classification of Diseases, Ninth Revision, Clinical Modification (ICD-9-CM) code 428.0) between July 1, 2012, and June 30, 2014, and followed patients through until October 31, 2015. The study was considered exempt from the Institutional Review Board of Albert Einstein College of Medicine. We used 2010 median household income by dwelling zip code from the United States Census Bureau ${ }^{5}$ as a surrogate for socioeconomic status. Information regarding inpatient mortality was retrieved from electronic medical records.

\section{RESULTS}

Medical records of 2735 consecutive adult heart failure patients from 2012 to 2014 were reviewed; among them, 642 had LVEF $\leq 35 \%$ on transthoracic echocardiogram (TTE). The following groups were excluded from analysis: 88 had prior ICD implantation; 130 were followed by physicians outside our facility or had no follow-up

Published online July 3, 2018 outpatient visit; 45 died during the index admission; and 2 received ICD as secondary prevention (see Fig. 1).

The final cohort consisted of 377 patients (mean age 64 \pm 15 years, female $34 \%$ ) of which 106 had persistently low LVEF. Table 1 shows the baseline demographic characteristics of the study population. The majority of patients were Black (42\%) or Hispanic (22\%), and $80 \%$ had dwelling zip codes associated with median household income $\leq \$ 50,000$.

ICDs were implanted in 27 (25\%) of these 106 patients, and only 19 received P-ICD within 1 year of repeat TTE showing LVEF $\leq 35 \%$. The median time between repeat TTE and ICD placement was 3 months (interquartile range 1-19 months). For patients who had repeat TTEs, 47\% (108 out of 231 patients) eventually had improvement of their EFs to above 35\%. Among the 79 patients who had persistently low LVEF but did not receive ICD, 23 (29\%) refused, $22(28 \%)$ were lost to follow-up, 10 (13\%) were non-compliant to medication/appointment and thus not able to achieve guideline-directed medical therapy for heart failure, $4(5 \%)$ were not referred to cardiologists, $10(13 \%)$ were still under evaluation, $1(1 \%)$ was not referred by cardiologists to electrophysiologists, 2 (2\%) had a cardiac arrest and died in the hospital during the evaluation period for an ICD, 7 (9\%) died from other causes (heart failure, 4; stroke, 1; HIV, 1; diarrhea and altered mental status, 1).

We were able to collect the following reasons for refusal of ICDs from retrospective review of medical records: relatively well-preserved exercise tolerance and disbelief in the possibility of sudden cardiac death in 5 patients, anxiety toward invasive procedures in 4 , fear of device malfunction in 1 , religious beliefs in 1 patient, hesitancy and no specific reason mentioned in 12 patients.

\section{DISCUSSION}

To our knowledge, our study is the first investigation on the use of P-ICD implantation in an underserved patient population. In our study, underutilization of ICDs and a significant delay in ICD placement were observed and could potentially lead to lethal outcomes. In this 
Table 1 Demographics

\begin{tabular}{|c|c|c|c|c|c|c|c|}
\hline \multirow[b]{3}{*}{ Characteristics } & \multirow{3}{*}{$\begin{array}{l}\text { Overall } \\
\overline{(n=377)}\end{array}$} & \multicolumn{3}{|c|}{ ICD candidate } & \multicolumn{3}{|c|}{$\begin{array}{l}\text { ICD implantation among ICD } \\
\text { candidates }\end{array}$} \\
\hline & & \multirow{2}{*}{$\frac{\text { No }}{(n=271)}$} & \multirow{2}{*}{$\frac{\text { Yes }}{(n=106)}$} & \multirow[t]{2}{*}{$p$ value } & \multirow{2}{*}{$\frac{\text { No }}{(n=79)}$} & \multirow{2}{*}{$\frac{\text { Yes }}{(n=27)}$} & \multirow[t]{2}{*}{$p$ value } \\
\hline & & & & & & & \\
\hline Age, mean(SD), year & $64(15)$ & $64(15)$ & $62(14)$ & 0.25 & $62(15)$ & $63(11)$ & 0.98 \\
\hline Age groups, year & & & & 0.04 & & & 0.10 \\
\hline$<55$ & $113(30)$ & $80(30)$ & $33(31)$ & 0.76 & $28(35)$ & $5(19)$ & 0.15 \\
\hline $55-64$ & $94(25)$ & $72(27)$ & $22(21)$ & 0.24 & $13(16)$ & $9(33)$ & 0.10 \\
\hline $65-74$ & $78(21)$ & $47(17)$ & $31(29)$ & 0.01 & $21(27)$ & $10(37)$ & 0.33 \\
\hline$\geq 75$ & $92(24)$ & $72(27)$ & $20(19)$ & 0.12 & $17(22)$ & $3(11)$ & 0.27 \\
\hline Female & $129(34)$ & $96(35)$ & $33(31)$ & 0.43 & $23(29)$ & $10(37)$ & 0.48 \\
\hline Race & & & & $<0.01$ & & & 0.12 \\
\hline Black & $158(42)$ & $108(40)$ & $50(47)$ & 0.20 & $39(49)$ & 11(41) & 0.44 \\
\hline Hispanic & $82(22)$ & $51(19)$ & $31(29)$ & 0.03 & $19(24)$ & $12(44)$ & 0.04 \\
\hline White & $48(13)$ & $41(15)$ & $7(7)$ & 0.03 & $7(9)$ & $0(0)$ & 0.19 \\
\hline Asian & $16(4)$ & $8(3)$ & $8(8)$ & 0.08 & $5(6)$ & $3(11)$ & 0.42 \\
\hline Other & 73 (19) & $63(23)$ & $10(9)$ & $<0.01$ & $9(11)$ & $1(4)$ & 0.45 \\
\hline $\begin{array}{l}\text { Median income at dwelling } \\
\text { zip code, in US dollars }\end{array}$ & & & & $<0.01$ & & & 0.17 \\
\hline$<35,000$ & $125(33)$ & $78(29)$ & $47(44)$ & $<0.01$ & $36(46)$ & $11(41)$ & 0.66 \\
\hline $35,000-50,000$ & $179(47)$ & $142(52)$ & $37(35)$ & $<0.01$ & $24(30)$ & $13(48)$ & 0.09 \\
\hline$>50,000$ & 73 (19) & $51(19)$ & $22(21)$ & 0.67 & $19(24)$ & $3(11)$ & 0.18 \\
\hline
\end{tabular}

ICD, implantable cardioverter-defibrillator; SD, standard deviation

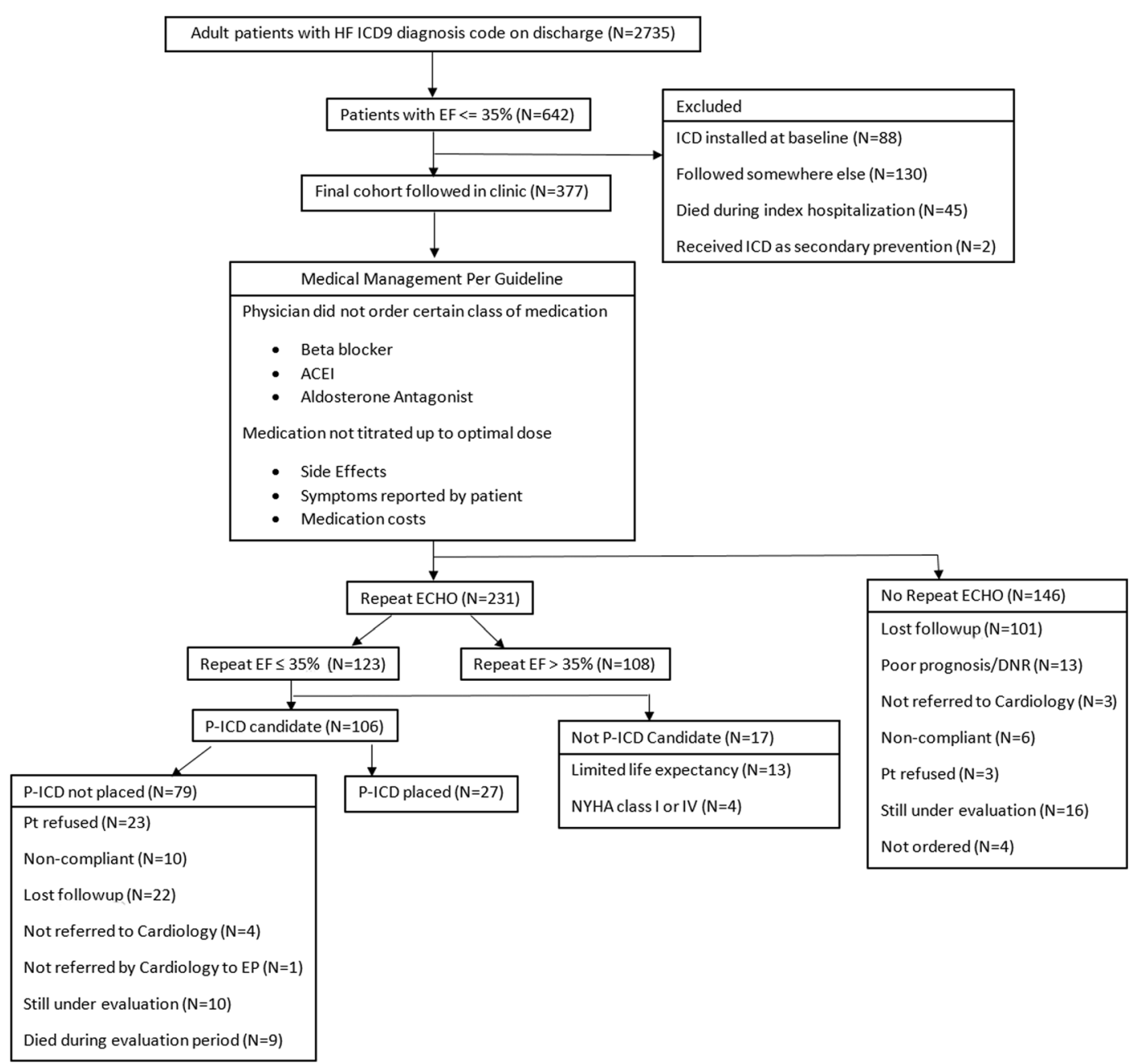

Figure 1 Patient selection flowchart. The arrows denote the level in which various factors led to the exclusion of patients. HF, heart failure; ICD9, International Classification of Diseases, Ninth Revision; ICD, implantable cardioverter-defibrillator; EF, ejection fraction; ACEI, angiotensin-converting-enzyme inhibitor; ECHO, echocardiogram; P-ICD, ICD for primary prophylaxis; NYHA, New York Heart Association. 
population, there were significant barriers to having ICD placement, such as patient compliance, loss to follow-up, and patient refusal. Future studies should investigate methods to improve ICD implantation rate and reduce the delay. Given that nearly all patients eligible for ICD placement were given referrals to cardiologists, future research should focus on overcoming the barriers in specialty clinics and the facilitation of such consultations in primary care clinics.

Our study has its limitations: it was a single-center study conducted in an underserved patient population in an innercity public municipal teaching hospital, and thus the results may not be generalizable to other settings.

ACKNOWLEDGEMENTS: We would like to acknowledge Krysthel Engstrom, MD, for her assistance with the IRB submission; Francesca Cossarini, MD, for initiating the idea for this project; The Hung Nguyen, MD, for preliminary screening of subjects; Luise Holzhauser, $M D$, for coordinating the research project; and Michael Grushko, MD, for reviewing the earlier version as a poster.

Corresponding Author: Robert Faillace, MD, ScM; Jacobi Medical Center, Albert Einstein College of Medicine, Bronx, NY, USA (e-mail: robert.faillace@nbhn.net).

\section{Compliance with Ethical Standards:}

Prior Presentations: We presented an earlier version of the manuscript as a poster at the 65th American College of Cardiology annual scientific session in Chicago, in March 2016.

Conflict of Interest: The authors declare that they have no conflict of interest.

\section{REFERENCES}

1. Bardy GH, Lee KL, Mark DB, et al. Amiodarone or an implantable cardioverter-defibrillator for congestive heart failure. N Engl $\mathrm{J}$ Med 2005;352(3):225-237.

2. Moss AJ, Hall WJ, Cannom DS, et al. Cardiac-resynchronization therapy for the prevention of heart-failure events. N Engl J Med 2009;361(14): 1329-1338.

3. Epstein AE, Dimarco JP, Ellenbogen KA, et al. ACC/AHA/HRS 2008 guidelines for Device-Based Therapy of Cardiac Rhythm Abnormalities: executive summary. Heart Rhythm 2008;5(6):934-955.

4. Epstein AE, DiMarco JP, Ellenbogen KA, et al. 2012 ACCF/AHA/HRS focused update incorporated into the ACCF/AHA/HRS 2008 guidelines for device-based therapy of cardiac rhythm abnormalities: a report of the American College of Cardiology Foundation/American Heart Association Task Force on Practice Guidelines and the Heart Rhythm Society. J Am Coll Cardiol 2013;61(3):e6-75.

5. Michigan Population Studies Center (n.d.) Zip code characteristics: mean and median household income. Available at http://www.psc.isr.umich. edu/dis/census/Features/tract2zip/. Accessed 5 June 2018. 